Article

\title{
The effect of plasma activated medium and PBS on human melanoma cells compared with other cancer and normal cells
}

\author{
Dominika Sersenová ${ }^{1 *}$, Zdenko Machala ${ }^{1 *}$, Vanda Repiská ${ }^{2}$, Helena Gbelcová ${ }^{2}$ \\ 1 Faculty of Mathematics, Physics and Informatics, Comenius University in Bratislava, Slovakia \\ 2 Faculty of Medicine, Comenius University in Bratislava, Slovakia \\ *D.S. dominika.sersenova@fmph.uniba.sk, Z.M. zdenko.machala@fmph.uniba.sk
}

Simple Summary: Plasma activated liquids (PAL) can have anticancer effects and act selectively between cancer and normal cells. They represent a possible new anticancer therapy with a relatively easy clinical application. The objective of this study was to activate cell growth media and phosphate buffered saline by streamer corona discharge in ambient air, which enriched them with reactive oxygen and nitrogen species, here in optimum ratio of hydrogen peroxide and nitrites. Both PAL decreased the cell viability and induced apoptosis in three human cancer cell lines (melanoma, glioblastoma and pancreatic cancer), while no apoptosis was observed in normal primary human dermal fibroblasts upon sensitive plasma activation. Moreover, the first 30 minutes of cancer cell incubation in PAL were enough to start processes leading to the cell death. The observed selectivity of PAL effects was dependent on correctly chosen plasma activation time and PAL concentration.

Abstract: Plasma medicine is a new field focusing on biomedical and clinical applications of cold physical plasmas, including their anticancer effects. Cold plasmas can be applied directly or indirectly as plasma activated liquids (PAL). The effect of plasma activated cell growth medium (PAM) and plasma activated phosphate buffered saline (PAPBS) were tested using a plasma pen generating streamer corona discharge in ambient air, on different cancer cell lines (melanoma A375, glioblastoma LN229 and pancreatic cancer MiaPaCa-2) and normal cells (human dermal fibroblasts HDFa). The viability reduction and apoptosis induction were detected in all cancer cells after incubation in PAL. In melanoma cells we focused on detailed insights to the apoptotic pathways. The anticancer effects depend on the plasma treatment time or PAL concentration. The first 30 minutes of incubation in PAL were enough to start processes leading to the cell death. In fibroblasts, no apoptosis induction was observed, only PAPBS, activated for longer time, slightly decreased their viability. Anticancer effects of PAM and PAPBS on cancer cells showed selectivity compared to normal fibroblasts, depended on correctly chosen activation time and PAL concentration. This selectivity, supported by optimum ratio of hydrogen peroxide and nitrites in PAL, is very promising for potential clinical applications.

Keywords: cold plasma, plasma activated liquid, cancer cell, melanoma, fibroblast

\section{Introduction}

Plasma medicine is relatively new interdisciplinary field of medicine with the goal of therapeutic applications of cold atmospheric plasmas on human organism. Cold plasma is already used in some countries to sterilise medical equipment [1] or to enhance wound healing [2] and more clinical applications are being developed including cancer therapy [3,4].

Plasma is an ionized gas formed by electrons, positively and negatively charged ions, photons and neutral atoms and molecules including radicals [5]. Cold atmospheric plasma can be generated in strong electric field and its overall macroscopic (gas) temperature can be kept as low as at room temperature while keeping high energy electrons. Therefore, it is suitable for applications on thermosensitive materials, as well as living cells and tissues [6]. All biological effects of cold plasma 
are induced by physical factors (electromagnetic field, radiation) or chemical factors, mostly reactive oxygen and nitrogen species (RONS) generated by the plasma. In this work we focus on indirect plasma treatment with so called plasma activated (stimulated) liquids (PAL) - liquids that were treated with plasma and subsequently added to cells. Upon PAL application, the only factor affecting the cells are RONS [7], which are considered as key agents in plasma therapy [8]. RONS naturally play an important role in many physiological processes, but it is difficult to exactly isolate their function. Although RONS also contribute in cell proliferation, it has been shown that plasma can increase their intracellular concentration and can activate different signalling pathways in cells. Low concentration increase of RONS is well tolerated because they are neutralized by the action of protective enzymes, such as superoxide dismutase or catalase. The effect of higher concentration of reactive oxygen species is already used in different cancer therapies, for example in radiotherapy, photodynamic therapy or some types chemotherapy [9], but the action of plasma generated RONS in PAL is milder, because they are present only in extracellular environment. It has been shown that there is a therapeutical window, when plasma do not harm healthy cells, but induce apoptosis in cancer cells $[10,11]$. However, it is needed to find the right plasma treatment for each plasma source and geometry $[3,12]$. In most studies, plasma is generated by plasma jets using noble gases $(\mathrm{He}, \mathrm{Ar})$, which contribute to different RONS production and composition than discharges in ambient air.

Dynamics of chemical species evolution in plasma discharge is very complex, therefore the exact types of RONS or their chemical reactions have to be studied in more details [13] as well as their interaction with liquids and living cells or tissues. As the most important RONS generated in PAL are considered $\mathrm{H}_{2} \mathrm{O}_{2}, \mathrm{OH}, \mathrm{HO}_{2}, \mathrm{O}^{1}{ }^{1} \mathrm{O}_{2}, \mathrm{O}_{2} \cdot, \mathrm{O}_{3}, \cdot \mathrm{NO}, \mathrm{NO}_{2}, \mathrm{NO}_{2}^{-}, \mathrm{NO}_{3^{-}}$, ONOO- and chlorine reactive species, if the liquid environment contains $\mathrm{Cl}[10,14-16]$. $\mathrm{H}_{2} \mathrm{O}_{2}$ alone in higher concentrations acts cytotoxically, but when the more specific and selective effect is required, other mechanisms must be applied. The synergistic effect of $\mathrm{H}_{2} \mathrm{O}_{2}$ and $\mathrm{NO}_{2}{ }^{-}$was shown when killing cancer cells $[9,17-19]$ while the role of $\mathrm{NO}_{3}$ - is not clearly established. Typically, no additional effect of $\mathrm{NO}_{3}{ }^{-}$was observed $[15,19]$, although in some studies a different cell viability was achieved by varying $\mathrm{NO}_{3}$ - concentration [12]. Short-lived peroxynitrite $\mathrm{ONOO}^{-}$and singlet delta oxygen ${ }^{1} \mathrm{O}_{2}$ also play important roles in contribution to anticancer effects $[17,20]$.

PAL have potential in clinical anticancer applications and are safer for a patient than a direct plasma treatment, who needs not a direct contact with high voltage. PAL can be injected into the tissues, even where the direct plasma treatment is not possible, for example in peritoneal treatment or treatment of micrometastases. PAL keep their anticancer properties for a longer time, so they can be prepared in advance and stored [21], [22]. In this work we focus on two PAL - plasma activated cell growth medium (PAM) and plasma activated phosphate buffered saline (PAPBS). The anticancer effects of plasma activated water or plasma activated Ringer lactate solution have been also investigated [23].

The studies on PAM conducted only in last decade [24], showed that PAM can reduce cell viability in different cancer cell lines - glioblastoma [24-26], breast cancer [22], [25], bladder cancer [27], lung cancer [22], hepatic cancer [22], colorectal [28] or ovarian cancer [29] cells including chemoresistant ovarian carcinoma cells [30]. Plasma application does not seem cause so many side effects as the current cancer therapies and the in vitro and first in vivo animal experiments propose its universal use on different cancer types. Recent studies revealed that plasma can induce immunogenetic cell death by expressing damage-associated molecular patterns (for example calreticulin) in the cancer cells after plasma treatment [31]. It means that the clinical application of plasma (and PAL) could lead to better results than those observed in vitro or in vivo on immunosuppressed mice, because the patient's own immune system could contribute in fighting against the cancer.

Although the anticancer effects of PAM are very promising, detailed insight into their chemical changes are difficult, because of their complex composition and many possible reactions between RONS and medium compounds. Therefore, other, more simple liquids, such as phosphate buffer saline (PBS), are being studied, although there are still not as many studies on PAPBS than on PAM $[15,23]$. Another advantages of PBS in in vitro experiments is that it is not cell line specific as cell growth media, and if the plasma treatment is accurate, the $\mathrm{pH}$ of this buffered solution remains 
physiological (plasma activated water or other non-buffered solutions typically become acidic after plasma treatment [20]). PAPBS was shown capable of decreasing viability in glioblastoma cells $[15,23]$ or pancreatic cancer cells [23].

Systematic studies with PAM and PAPBS on normal cells are still lacking, but selective effect on cancer cells was observed in study comparing PAM application on glioblastoma cells and astrocytes [24], although the same activated PAM decreased fibroblasts proliferation by $40 \%$ [26]. PAM also decreased viability of breast cells [5].

In this work we studied both PAM and PAPBS activated by streamer corona discharge in ambient air, unlike most of studies that typically use plasma jets operating with noble gases. Ambient air used as a plasma generating gas is cheaper, broadly available, and is good precursor of RONS. This makes our portable plasma pen unique and easily applicable in future clinical practise worldwide. The same plasma source and PAM have been successfully tested in vitro to induce apoptosis in several cancer cell lines and the key possible mechanisms responsible for the plasma and PAM selectivity have been identified, especially the role of secondary ${ }^{1} \mathrm{O}_{2}$ inactivating the protective catalase on the membranes of cancer cells [14,32].

Here, the focus is set primarily on the effect of plasma activated liquids on human melanoma cells A375. Melanoma is one of the most aggressive types of cancer and the deadliest skin cancer with around 200000 new cases detected annually [33]. The occurrence of melanoma on the human skin makes it an easy target for plasma treatment with no surgical need. However, after metastases spread, PAL injections could be applicable.

Except the cell viability change upon exposure to PAM and PAPBS, the apoptosis induction was also investigated. Apoptosis, or programmed cell death, is an important and active regulatory pathway of cell growth and proliferation in healthy tissues. After plasma treatment, it is a desirable cell death type of cancer cells, because it does not cause significant inflammatory response in an organism [34]. In most studies that investigated plasma or PAL induced cell death type, apoptosis was confirmed [35], but necrosis also occurred [36]. Another still unclarified question is the exact mechanisms or cell signalling pathways, which are activated by plasma to induce the cell death. Two main points in intracellular signalling are caspases and mitochondria, therefore the activity of caspase 3 and 7 and a change in mitochondrial membrane potential were studied here. Caspases are cysteine proteases with important roles in apoptosis propagating process in response to proapoptotic signals. The effector caspases, such as caspase 3 and 7, act further downstream and direct cellular breakdown through cleavage of structural proteins. Activation of these caspases is thus a hallmark of apoptosis. Mitochondria are crucial cell organelles and contain key regulators of cell death processes. Mitochondrial membrane potential changes have been implicated in apoptosis, necrotic cell death, and caspase-independent cell death processes. Depolarization of the inner mitochondrial membrane potential is thus an indicator of the mitochondrial dysfunction and cellular health, which has become increasingly important in the study of apoptosis, drug toxicity and multiple disease states.

PAL in this article was also applied on normal dermal fibroblasts to study the potential selective effect of PAL treatment, and on two other epithelial cancer cell lines (pancreatic cancer and glioblastoma cells) to examine a more general plasma use in cancer therapy.

\section{Materials and Methods}

\subsection{Cell culture and cultivation}

Four adherent human cell lines were used to study the effect of plasma activated liquids melanoma cells A375, pancreatic cancer cells MiaPaCa-2, glioblastoma cells LN229; and noncancerous primary fibroblasts HDFa. A375 and MiaPaCa-2 were cultivated in Dulbecco's modified Eagle medium (DMEM, Sigma-Aldrich) supplemented with 10\% fetal bovine serum (Sigma-Aldrich), LN229 in DMEM (Gibco) supplemented with 10\% fetal bovine serum and $2 \mathrm{mM}$ glutamine (SigmaAldrich) and HDFa cells in fibroblasts growth medium (Cell Applications). The cells were cultivated in $95 \%$ humidified atmosphere with $5 \% \mathrm{CO}_{2}$ at $37^{\circ} \mathrm{C}$. 
The cells were seeded in 96-well or 6-well plates according the type of cell analysis, 24 hours before the application of plasma activated liquids.

Morphological changes of cells were observed, and pictures were taken by microscope Zeiss Axio Verte.A1 with CCD camera Axiocam ICC 1 with Axio Vision 4.8 software.

\subsection{Plasma source and plasma liquid activation}

The portable plasma pen was used for plasma treatment of liquids to create PAL (Figure 1a and 1b). A DC positive streamer corona was generated in ambient atmospheric air between the tip of the needle electrode and the surface of the liquid. To keep the geometry of the system during the liquid activation constant, the liquid was placed in a glass bowl, the gap between the needle tip and surface of the liquid was $1 \mathrm{~cm}$, and the volume of the liquid was $5 \mathrm{ml}$. The grounded stainless-steel wire was dipped in the liquid onto the bowl bottom and the current was measured with by a current probe (Pearson 2878) and a digital oscilloscope (Tektronix TDS2024). The applied DC voltage was set at 12.8 $\mathrm{kV}$. The streamer corona in our setup and is a self-pulsing discharge with a maximum amplitude of one pulse 20-30 mA (Figure 1c), an average frequency $10 \mathrm{kHz}$ and a typical power $0.4 \mathrm{~W}$. Because of the low temperature, power and current, it is possible to directly treat live cells or tissues and the direct treatment of human skin is not painful when applied carefully.

Two different liquids were activated and applied to the cells - a phosphate buffered saline (PBS, Dulbecco A, OXOID) and a cell growth medium (the same as used for the cell cultivation, supplemented as described in part 2.1). Plasma activated liquids $(5 \mathrm{ml})$ were treated for $2.5,5,10$ or 15 minutes. The $\mathrm{pH}$, temperature and conductivity of the treated liquids did not change after plasma activation.

To treat cells with plasma activated PBS (PAPBS) or plasma activated medium (PAM), various combinations of treatment times, added volumes or incubation times were used.

a)

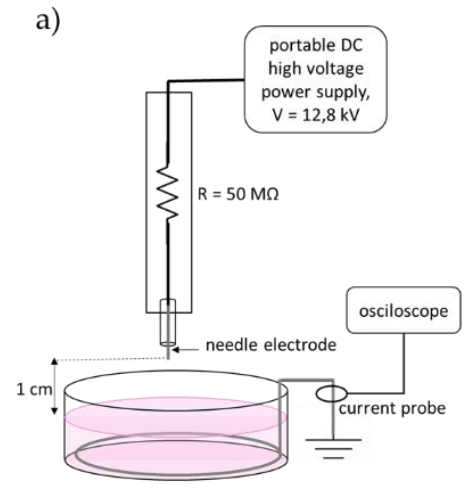

b)

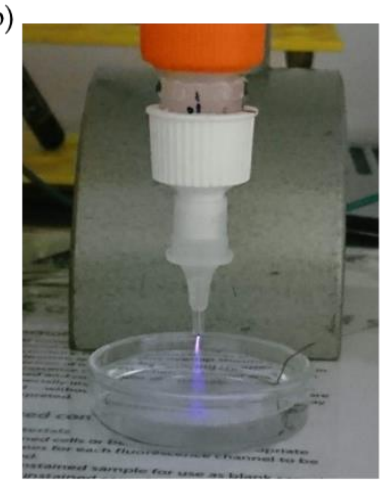

c)

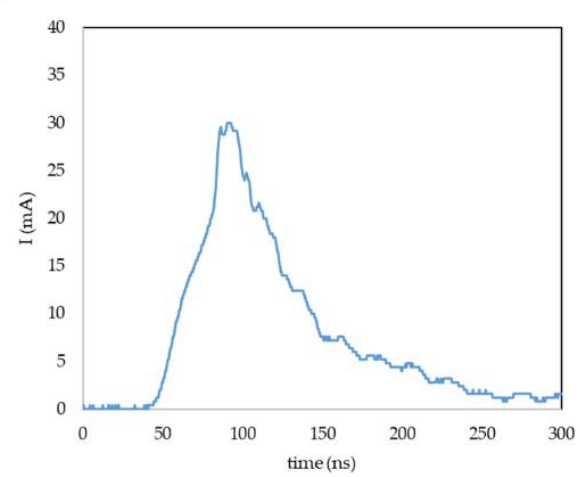

Figure 1. Streamer corona portable plasma pen and plasma activation of liquids, a) general setup of the plasma pen in liquid activation, b) photo of the PBS activation with streamer corona, c) example of one current pulse of the streamer corona discharge in the described geometry and voltage $12.8 \mathrm{kV}$.

\subsection{Chemical analysis of RONS in PAPBS}

Four different reactive species in PAPBS - $\mathrm{H}_{2} \mathrm{O}_{2}, \mathrm{NO}_{2}^{-}, \mathrm{NO}_{3}^{-}$and ozone - were measured by using spectrophotometric analysis. The absorption of samples was measured with UV-VIS spectrophotometer UV-1800 Shimadzu.

$\mathrm{H}_{2} \mathrm{O}_{2}$ analysis was performed by the titanium oxysulfate assay. The concentration of hydrogen peroxide was calculated from the absorption (at $407 \mathrm{~nm}$ ) of the yellow product formed in reaction between $\mathrm{TiOSO}_{4}$ and $\mathrm{H}_{2} \mathrm{O}_{2}$. To prevent $\mathrm{H}_{2} \mathrm{O}_{2}$ decomposition by its reaction with $\mathrm{NO}_{2}$, sodium azide $\left(\mathrm{NaN}_{3}, 60 \mathrm{mM}\right)$ was added to the sample immediately after plasma treatment.

Nitrite $\left(\mathrm{NO}_{2}-\right)$ concentration was evaluated with Griess reagents (Cayman Chemicals Nitrate/Nitrite Colorimetric Assay Kit \#780001). $\mathrm{NO}_{2}^{-}$with Griess reagents forms a purple complex 
with the absorption maximum at $540 \mathrm{~nm}$. To analyse nitrate $\left(\mathrm{NO}_{3}^{-}\right)$concentration, nitrate reductase was added first to the sample to reduce $\mathrm{NO}_{3}{ }^{-}$to $\mathrm{NO}_{2}{ }^{-}$, then analysed with Griess reagents as described before and $\mathrm{NO}_{3}{ }^{-}$concentration was calculated by the subtraction of previously measured $\mathrm{NO}_{2}-$ concentration.

Ozone dissolved in PAPBS was detected by using the indigo blue assay. The $\mathrm{O}_{3}$ decolorizes the indigo potassium trisulfonate dye and the concentration of ozone was calculated from the decrease of the absorbance at $600 \mathrm{~nm}$.

RONS in PAM have not been analysed due to its original pink colour and complex composition, which had interacted with chemical reagents that are standardized to measure RONS in liquids.

\subsection{Analysis of cell viability}

The effect of PAL on cells viability was evaluated by using the colorimetric metabolic MTT (3(4,5-dimethylthiazol-2-yl)-2,5-diphenyltetrazolium bromide) assay. The assay is based on a change of the yellow MTT into the purple formazan in viable cells, which can be dissolved in dimethyl sulfoxide and spectrophotometrically analysed at $490 \mathrm{~nm}$.

For inoculation 10000 cells (A375, LN229 and MiaPaCa-2) or 6000 cells (HDFa) in $100 \mu \mathrm{l}$ medium per well of 96-well plates were used. The PAL were applied to the cells 24 hours after their seeding. Cell medium was either completely replaced with $100 \mu \mathrm{PAL}$ or PAL was added to the cells in a ratio 1:1 with already present medium, so the final concentration of PAPBS or PAM was 100\%, or $50 \%$ respectively. The cells were incubated with PAPBS/PAM for additional 24 hours or only 30 minutes and then replaced with an untreated medium for the rest of the time until the $24 \mathrm{~h}$ incubation (we called this treatment "washing"). The control cells were treated in the same way with untreated PBS and medium.

The viability of the samples was normalized to the control cell sample incubated in the medium.

\subsection{Analysis of apoptotic cell death with annexin $V$}

The percentage of apoptotic cells was determined with Muse Annexin V \& Dead Cell Kit and a flow cytometer Muse Cell analyser. The assay contains two fluorescent cell dyes - annexin V, which dyes phosphatidylserine located on the outer surface of cell membranes during apoptosis, and 7$\mathrm{AAD}$ as an indicator of the cell membrane integrity, which marks late apoptotic and dead cells. The method enables to distinguish live cells, early and late apoptotic cells and dead cells (which died in a non-apoptotic pathway).

Cells were seeded in 6-well plates in amount of 250000 (A375, LN229 and MiaPaCa-2) or 150000 (HDFa) cells per well in $2.5 \mathrm{ml}$ of liquid. The confluence and volume were kept proportional with the viability experiment. The cells were treated with PAL in the same way as described in section 2.424 hours after seeding, which means that the medium was either replaced with $2.5 \mathrm{ml}$ PAL, or PAL was just added to the wells in a ratio 1:1 to the present medium. The cells were incubated with PAL either for 24 hours or for 30 minutes, after which PAL was removed and cells were incubated in untreated medium until 24-hour incubation ("washing").

After additional 24 hours all the liquid from the well and cells released from the bottom by using trypsin were centrifuged and cells prepared for the analysis according to the Muse kit protocol and analysed with Muse flow cytometer.

\subsection{Analysis of caspase $3 / 7$ activity}

The apoptosis status was evaluated based on effector caspases activation - caspase- 3 and caspase-7, which are considered as specific hallmarks of apoptosis. The caspase activity was measured with the Muse Caspase-3/7 Kit and the Muse Cell analyser. The kit contains 7-ADD dye to distinguish live and dead cells, and a Muse Caspase-3/7 reagent NucView to detect caspases activity. According to the fluorescent signal, the live cells, live with activated caspase-3/7 (apoptotic), dead with activated caspase-3/7 and dead cells (which died in non-apoptotic pathway) can be distinguished. 
The cells were seeded, treated and processed in the same way as described in section 2.5 and dyed according to the kit protocol.

\subsection{Analysis of mitochondrial potential changes}

The change in mitochondrial membrane potential - depolarisation, which is also considered as an early hallmark of apoptosis and cellular stress, was evaluated by using MitoPotential Kit containing fluorescent MitPotential and 7-ADD dye.

The cells were seeded, treated, processed in the same way as described in section 2.5 and dyed according to the kit protocol.

\subsection{Statistical analysis}

Statistical analysis was performed in Microsoft Excel and StatsDirect. The normality of data was tested, and data are presented as the average and the standard deviation of the mean. At least three independent repeated experiments were performed. The significance of plasma activated liquids effect was tested with two-sided t-test and the result was considered as significant if the $p<0.05$. The significant results are marked with * in the graphs.

\section{Results}

\subsection{RONS concentration}

Four long-lived RONS in plasma activated phosphate buffered solution were measured: hydrogen peroxide $\mathrm{H}_{2} \mathrm{O}_{2}$, nitrites $\mathrm{NO}_{2}$, nitrates $\mathrm{NO}_{3}{ }^{-}$and dissolved ozone $\mathrm{O}_{3}$, with spectrophotometric colorimetric methods (Figure 2). $5 \mathrm{ml}$ of PBS was treated for 2.5, 5 and 10 minutes with the streamer corona discharge in ambient air under the same conditions as the cell growth media and RONS were measured immediately after the plasma activation. The streamer corona discharge in ambient air was applied at low power $(\mathrm{P} \approx 0.4 \mathrm{~W})$, therefore even 15 minutes treatment of the liquid did not increase its temperature. The buffer also kept the $\mathrm{pH}$ of PBS unchanged after the treatment.

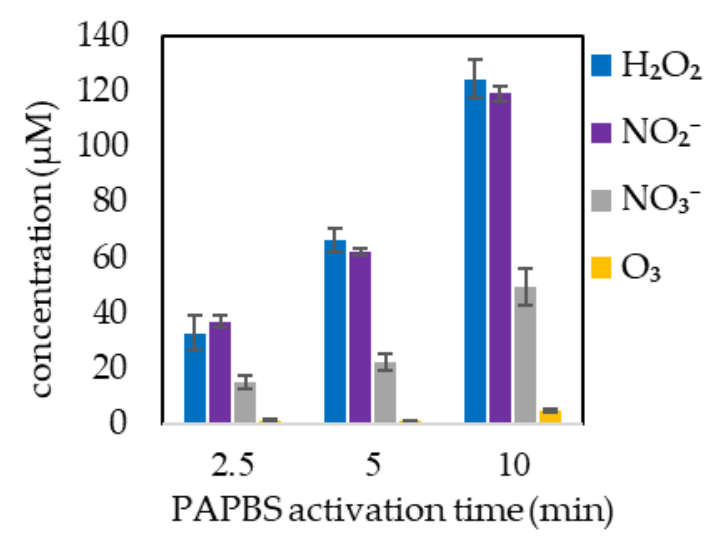

Figure 2. Hydrogen peroxide, nitrite, nitrate and ozone concentration in plasma activated PBS (PAPBS).

\subsection{Cells viability}

We evaluated the indirect effect of plasma activated liquids on the cells by measuring the cell viability. Viability was measured 24 hours from adding PAL. Analysis at 6, 48 or 72 hours after PAL application was performed too. However after 6 hours the effect just started to be observable and time periods longer than 24 hours of cell incubation ware too long for apoptosis tests, as after this time the most of the cells were in the late apoptosis state (as present in section 3.3) and started to disintegrate. Therefore, all presented data are from the analysis 24 hours after PAL application. To compare the treatment with $100 \%$ PAPBS, we added control treatment with cells incubated in untreated 100\% PBS (PBS(100\%)). When the cells were incubated in 50\% diluted PBS (PBS diluted 
with medium) or in the $100 \%$ PBS for 30 minutes only and then in a medium, there was no difference between these samples and control cells samples.

The main focus of our work was on melanoma A375 cells. The "dose" effect of the PAL can be clearly seen - with the increasing PAL concentration and with the increasing activation time, the decrease of cell viability was more significant (Figure 3). We observed this trend even in $25 \%$ and $12.5 \%$ PAL dilution, although these data are not presented in the graphs to keep it well readable. In most samples, the effects of PAM and PAPBS are comparable. However, the effect of $100 \%$ PAPBS compared to $100 \%$ PAM differs. $100 \%$ PAPBS decreased cell viability almost to $0 \%$ in all samples with no differences between activation times. To be able to test and compare these results, the cell viability of the sample incubated in 100\% PBS is shown, as an additive control, too. Although these cells in $100 \%$ PBS have significantly lower viability than the control cells in the medium, the difference between $100 \%$ PBS and 100\% PAPBS is obvious. Furthermore, only 30-minute incubation in PAM or PAPBS was enough to start processes leading to the decreased viability in cells.

The morphological change of the cells after 24-hour incubation with PAL was also notable (Figure 5). In PAL samples the significant amount of the cells was rounded, detached from the bottom, and a nuclear condensation was observed.

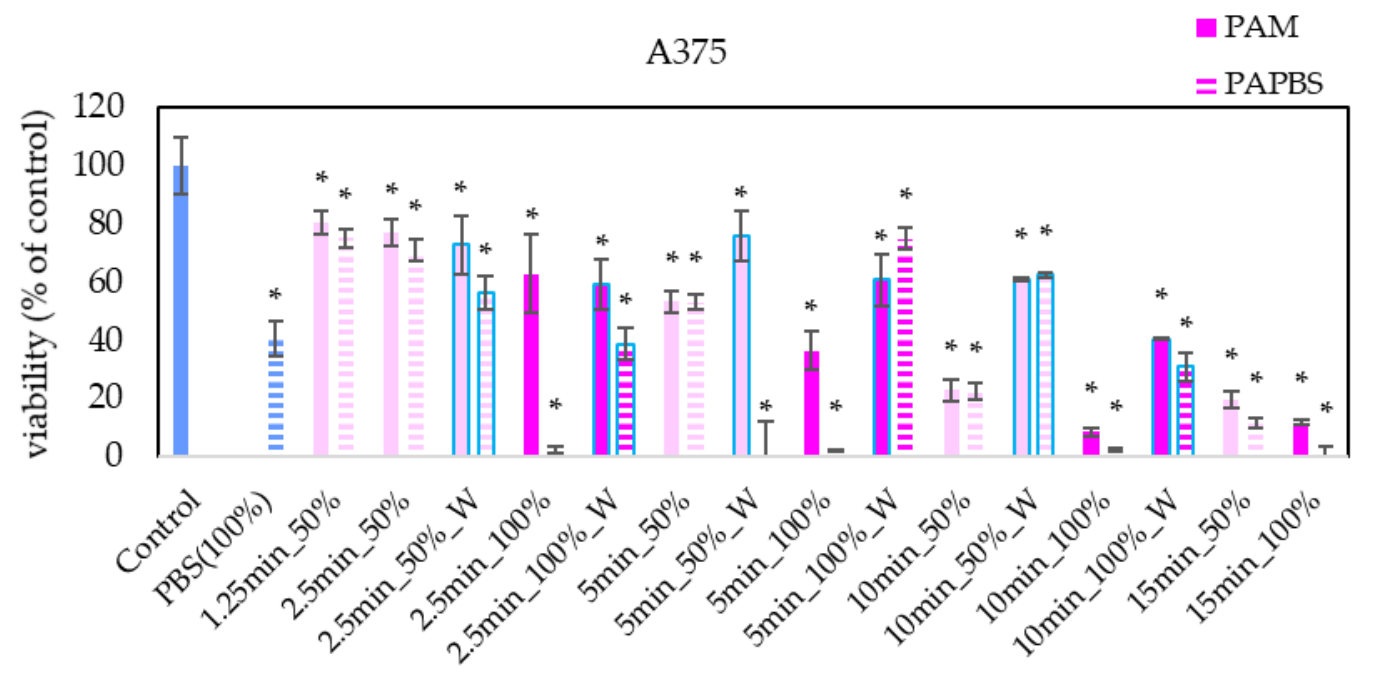

Figure 3. Effect of PAL on cell viability of human melanoma cells A375 24 hours after PAL application. Plasma activated medium (PAM) or plasma activated PBS (PAPBS) activated for 1.5, 2.5, 5, 10 or 15 minutes in 100\% or $50 \%$ concentration were used. Time of PAL action was 24 hours (without blue frames) or 30 minutes, after which PAL were replaced with untreated medium (W, blue frames). Significance of $100 \%$ PAPBS was tested compared to cells in $100 \%$ PBS, significance of other samples was tested compared to control. Viability was normalized to the control cells incubated in the medium.

PAM and PAPBS were applied on healthy skin cells (human dermal fibroblasts HDFa) to compare with their effects on melanoma cells (Figure 4). PAL activated for 2.5 minutes did not significantly affect the cell viability. We did not observe a significant viability change either after application of PAM activated for a longer time. Only PAPBS activated for 5 minutes lead to the viability decrease, when it was incubated with cells for 24 hours. In the case of $100 \%$ PAPBS, the 30minute incubation was enough to induce the viability change. On the other hand, in some samples, we also detected the opposite effect, i.e. a slight cell viability enhancement (mostly in $50 \%$ of 5 minutes treated PAM), but this effect was not statistically significant. 


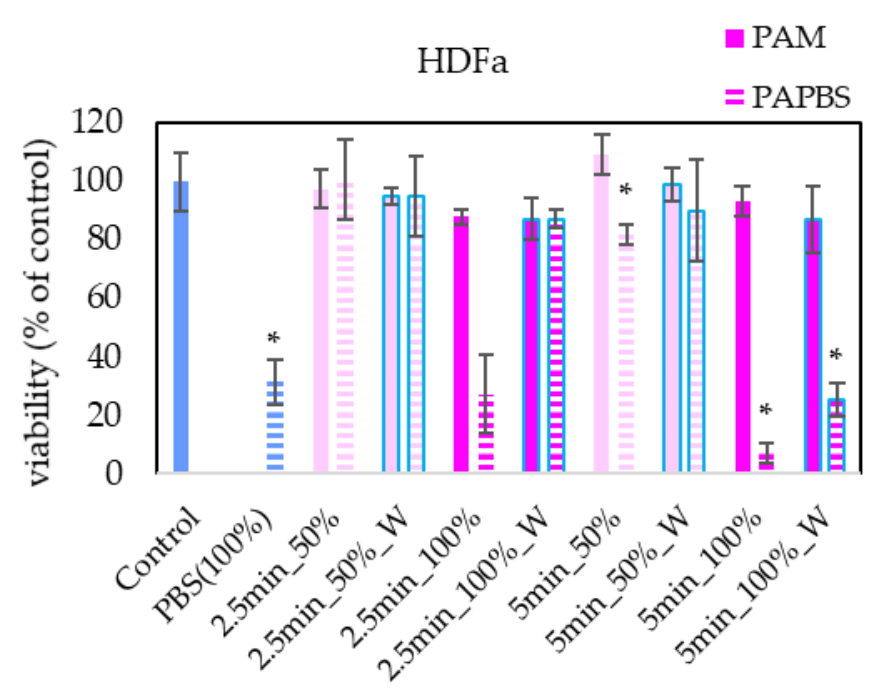

Figure 4. Effect of PAL on cell viability of human dermal fibroblasts HDFa 24 hours after PAL application. Plasma activated medium (PAM) or plasma activated PBS (PAPBS) activated for 2.5 or 5 minutes in $100 \%$ or $50 \%$ concentration were used. Time of PAL action was 24 hours (without blue frames) or 30 minutes, after which PAL were replaced with untreated medium (W, blue frames). Significance of $100 \%$ PAPBS was tested compared to cells in $100 \%$ PBS, significance of other samples was tested compared to control. Viability was normalized to the control cells incubated in the medium.
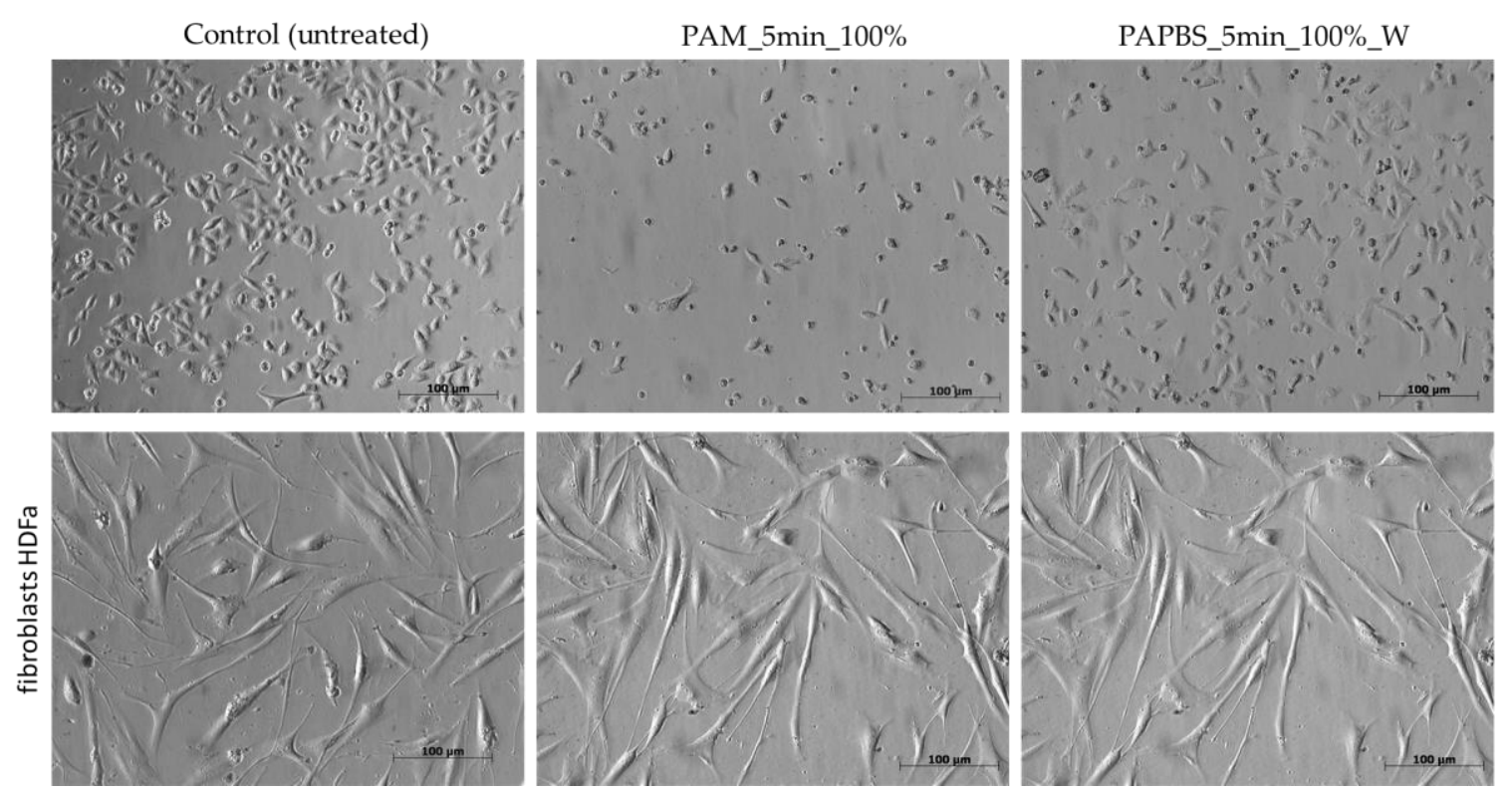

Figure 5. Effect of PAL on morphology of melanoma cells A375 and dermal fibroblasts HDFa 24 hours after PAL application. PAL were activated for 5 minutes. Two PAL treatments are showed - 100\% plasma activated medium (PAM) or $100 \%$ plasma activated PBS (PAPBS) incubated with cells for 30 minutes (W) and then replaced with the untreated medium. (Zeiss Axio Verte.A1 optical microscope)

The effect of PAL on A375 and HDFa was compared with other epithelial cancer cell lines: pancreatic cancer cells MiaPaCa-2 and glioblastoma cells (Figure 6). The advantage of MiaPaCa-2 cells is that they must be cultivated in exactly the same medium as melanoma A375 cells, so the possible difference in the effect would be only due to different properties of the cells and not due to the different medium composition. But in terms of viability, the effect of PAL on MiaPaCa-2 cells was mostly comparable with the effect on A375 cells. For LN229 cell cultivation a different brand of 
medium was used, although it is still the same type of high-glucose DMEM. The most sensitive cells to antiproliferative effect of PAL were LN229, in which even the PAL treated for 2.5 minutes reduced the cell viability to $20 \%$ or less.

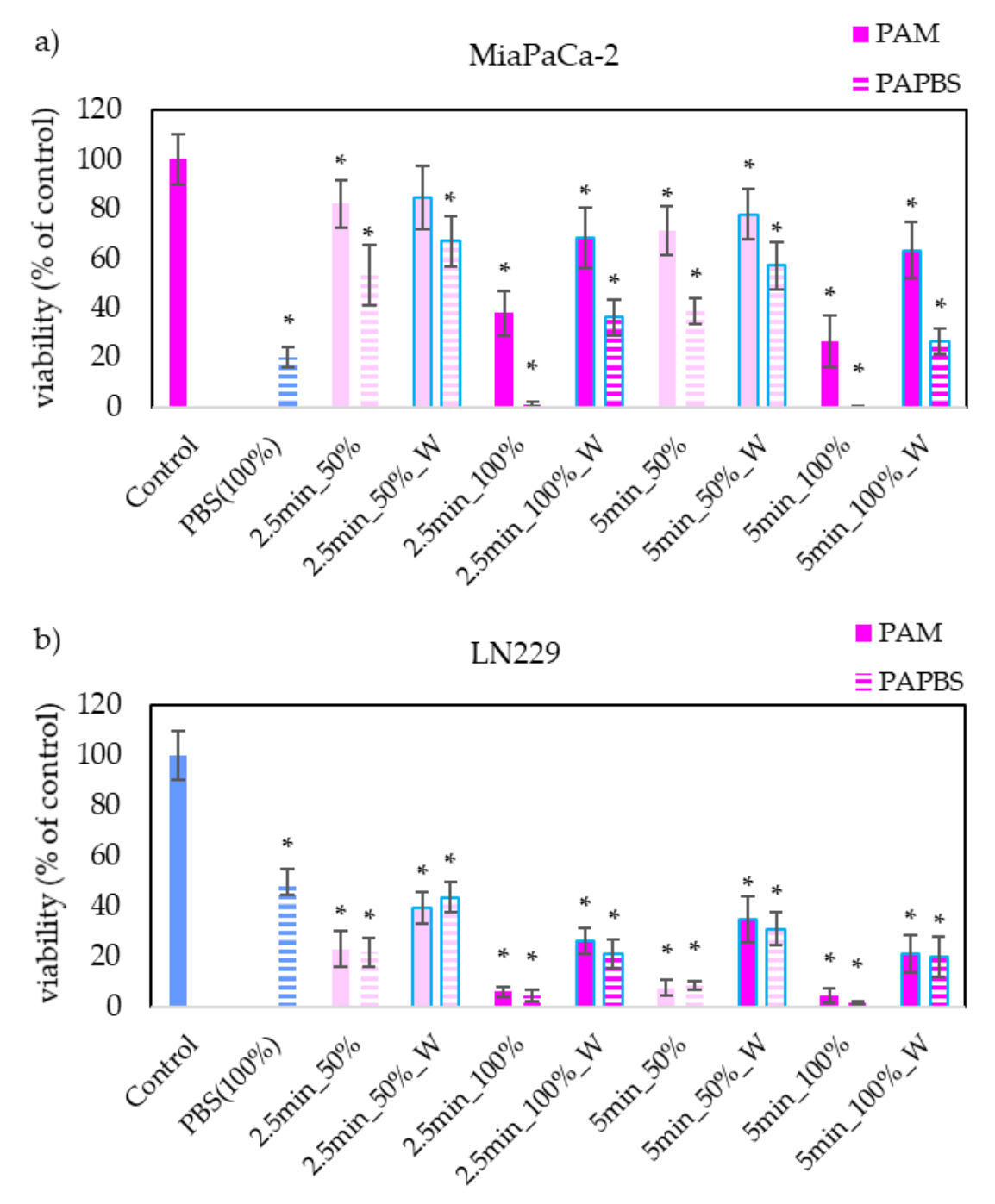

Figure 6. Effect of PAL on cell viability of pancreatic cancer cells (a) and glioblastoma cells (b) 24 hours after PAL application. Plasma activated medium (PAM) or plasma activated PBS (PAPBS) activated for 1.5, 2.5, 5, 10 or 15 minutes in $100 \%$ or $50 \%$ concentration were used. Time of PAL action was 24 hours (without blue frames) or 30 minutes, after which PAL were replaced with untreated medium (W, blue frames). Significance of $100 \%$ PAPBS was tested compared to cells in $100 \%$ PBS, significance of other samples was tested compared to control. Viability was normalized to the control cells incubated in the medium.

\subsection{Apoptosis detection}

To further analyse the effect of plasma activated liquids on the induction of cell apoptosis we used annexin $\mathrm{V}$ and 7-AAD staining. By combination of these dyes it is possible to distinguish live, early apoptotic, late apoptotic (dead) cells and non-apoptotic dead cells. We focused only on 5 minutes plasma activation time in most of the cell lines, because it showed the most promising results in cell viability. 2.5 minutes activation time was also studied in case of melanoma A375. To be able to compare treatment with 100\% PAPBS, an additional control sample with cells incubated in untreated $100 \%$ PBS (PBS(100\%)) was added. When the cells were incubated in 50\% PBS (PBS diluted with 
medium) or in PBS for 30 minutes only, there was no observed difference between the samples and control cells.

PAM and PAPBS activated for 2.5 and 5 minutes induced apoptosis in A375 cells (Figure 7), both in $100 \%$ and $50 \%$ concentration and even when PAL were replaced with the untreated medium after 30 minutes (W), the "dose" effect is observable. Almost all apoptotic cells were already considered as dead 24 hours after PAL application. Very low amount of the cells in non-apoptotic death (around $8 \%$ ) was observed, when $100 \%$ PBS or PAPBS for 24 hours was applied, whereas the effects of PAPBS and PBS were comparable. This indicated that the effect it is most likely caused by non-physiological conditions of the pure PBS, because there is no additional increase in dead non-apoptotic cells due to the plasma treatment in PAPBS.
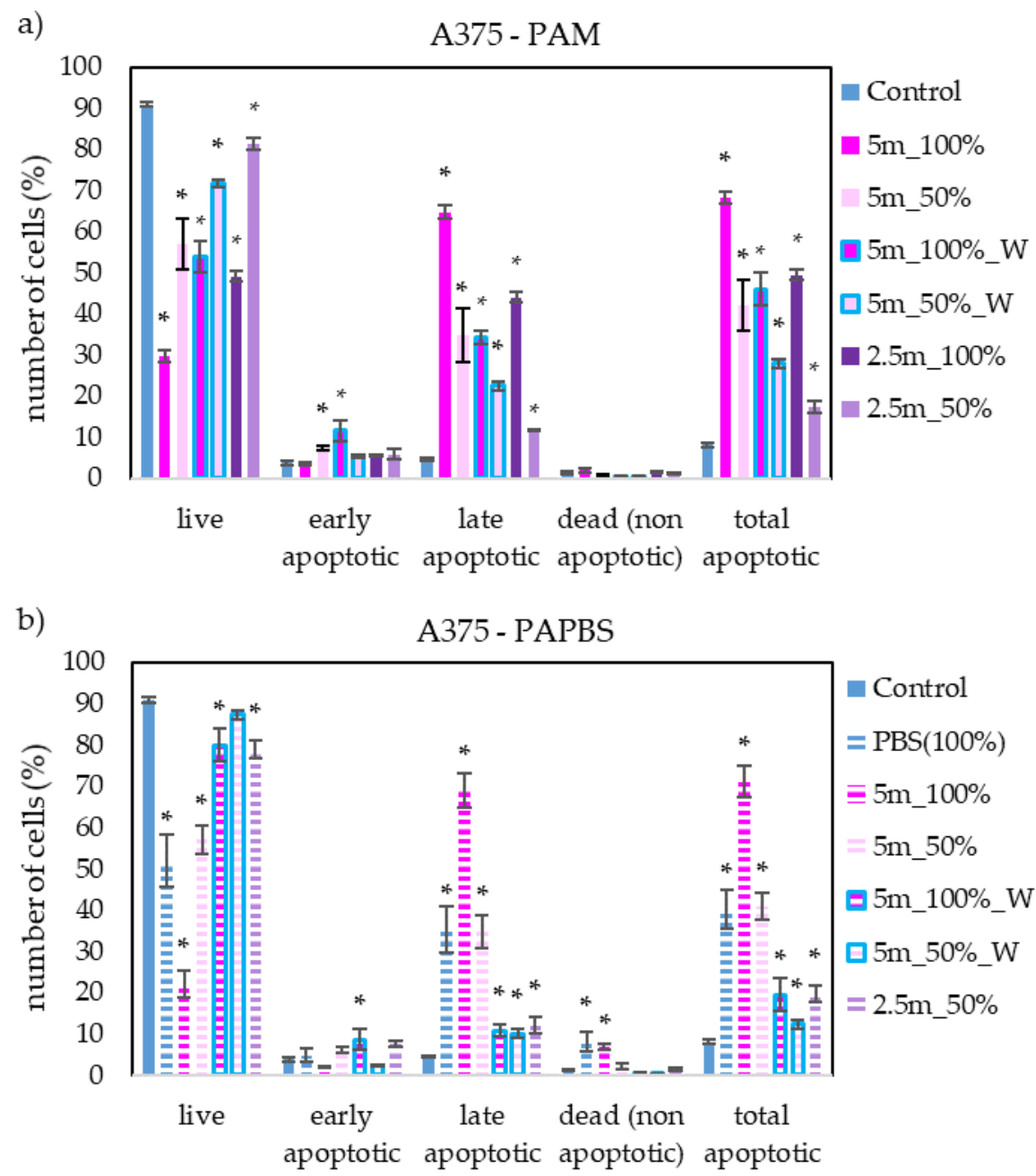

Figure 7. The effect of PAL on apoptosis induction in human melanoma cells A375, measured 24 hours after PAL application. Plasma activated medium - PAM (a) or plasma activated PBS - PAPBS (b) activated for 2.5 or 5 minutes in $100 \%$ or $50 \%$ concentration were used. Time of PAL action was 24 hours (without blue frames) or 30 minutes, after which PAL were replaced with untreated medium (W, blue frames). Significance of $100 \%$ PAPBS was tested compared to cells in $100 \%$ PBS, significance of other samples was tested compared to control.

The apoptosis or necrosis in HDFa cells was not detected in our experiments (Figure 8). We decided to analyse $100 \%$ PAPBS only when it was applied for 30 minutes, then replaced with untreated medium (W) since the primary cells were not capable survive in the 100\% PBS for 24 hours. Although in viability experiment the cell viability after applying PAPBS treated for 5 minutes (50\% or $100 \%$ W) decreased, stronger PAPBS could suppress proliferation of HDFa cells without leading to cell death. 


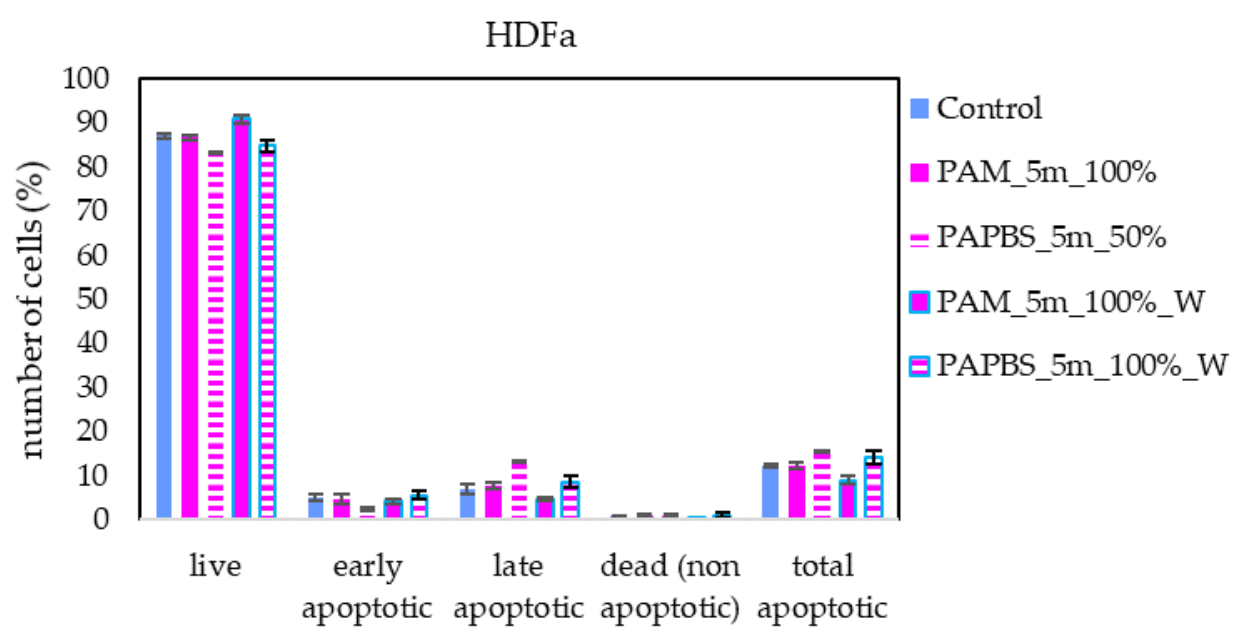

Figure 8. The effect of PAL on apoptosis induction in human dermal fibroblasts HDFa, measured 24 hours after PAL application. Plasma activated medium (PAM) or plasma activated PBS (PAPBS) activated for 5 minutes in $100 \%$ or $50 \%$ concentration were used. Time of PAL action was 24 hours (without blue frames) or 30 minutes, after which PAL were replaced with untreated medium (W, blue frames).

The apoptosis induction in MiaPaCa-2 and LN229 cells after PAM and PAPBS treatment was tested (Figure 9 and Figure 10). Although in MiaPaCa-2, there is high percentage of apoptotic cells even in control samples, enhancement in apoptotic cells after PAL application was significant. PAL successfully induced apoptosis also in LN229 cells, but according to the debris amount in the sample, many cells were already disintegrated, therefore the percentage of apoptotic cells in the time of analysis was lower than in the other cancer cell lines. The LN229 cells seem to be very sensitive to PAL and we can see around 10\% probably necrotic cells after incubation in 100\% PAPBS activated for 5 minutes. 

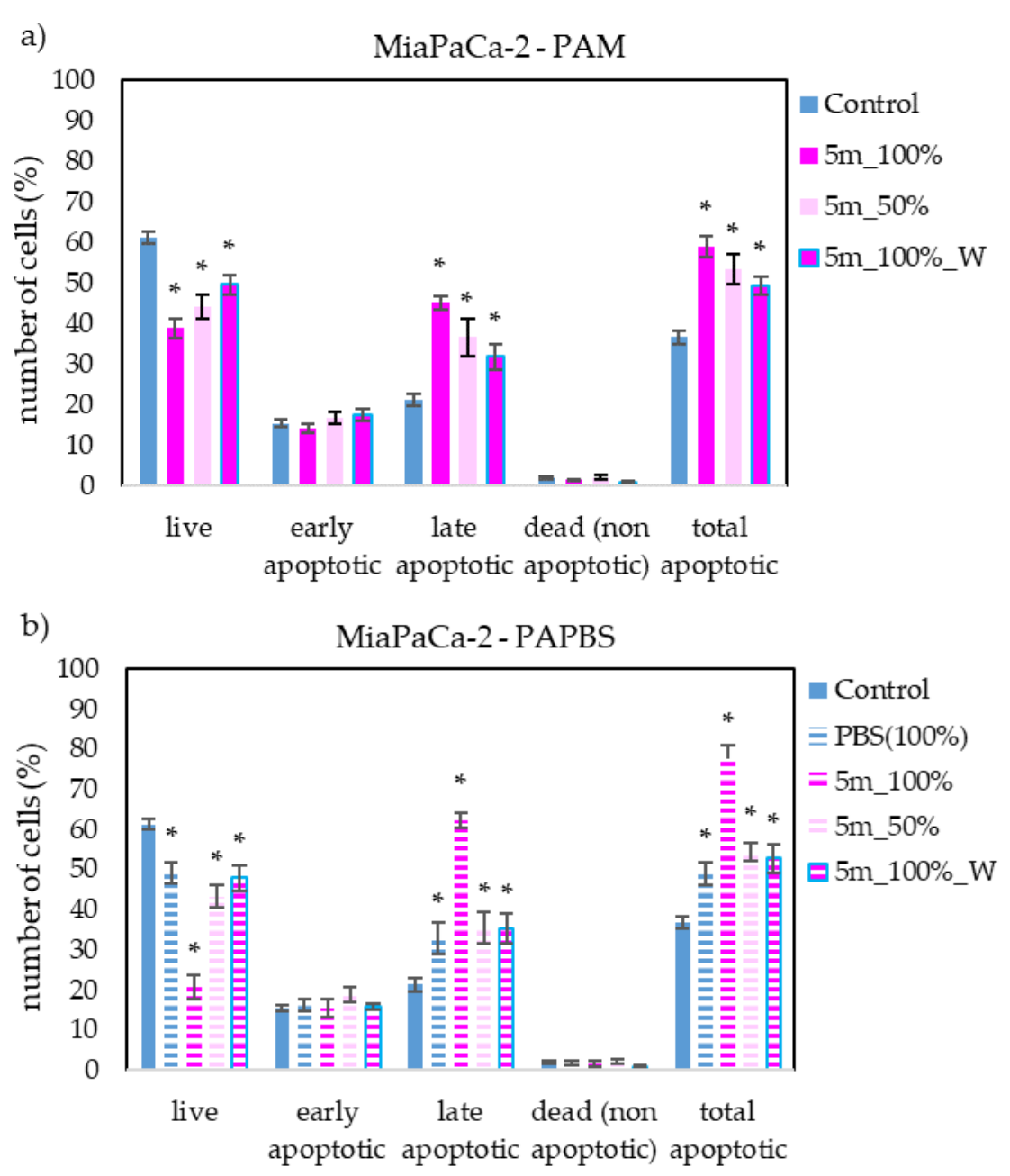

Figure 9. The effect of PAL on apoptosis induction in pancreatic cancer cells MiaPaCa-2, measured 24 hours after PAL application. Plasma activated medium - PAM (a) or plasma activated PBS - PAPBS (b) activated for 2.5 or 5 minutes in $100 \%$ or $50 \%$ concentration were used. Time of PAL action was 24 hours (without blue frames) or 30 minutes, after which PAL were replaced with untreated medium (W, blue frames). Significance of $100 \%$ PAPBS was tested compared to cells in $100 \%$ PBS, significance of other samples was tested compared to control. 

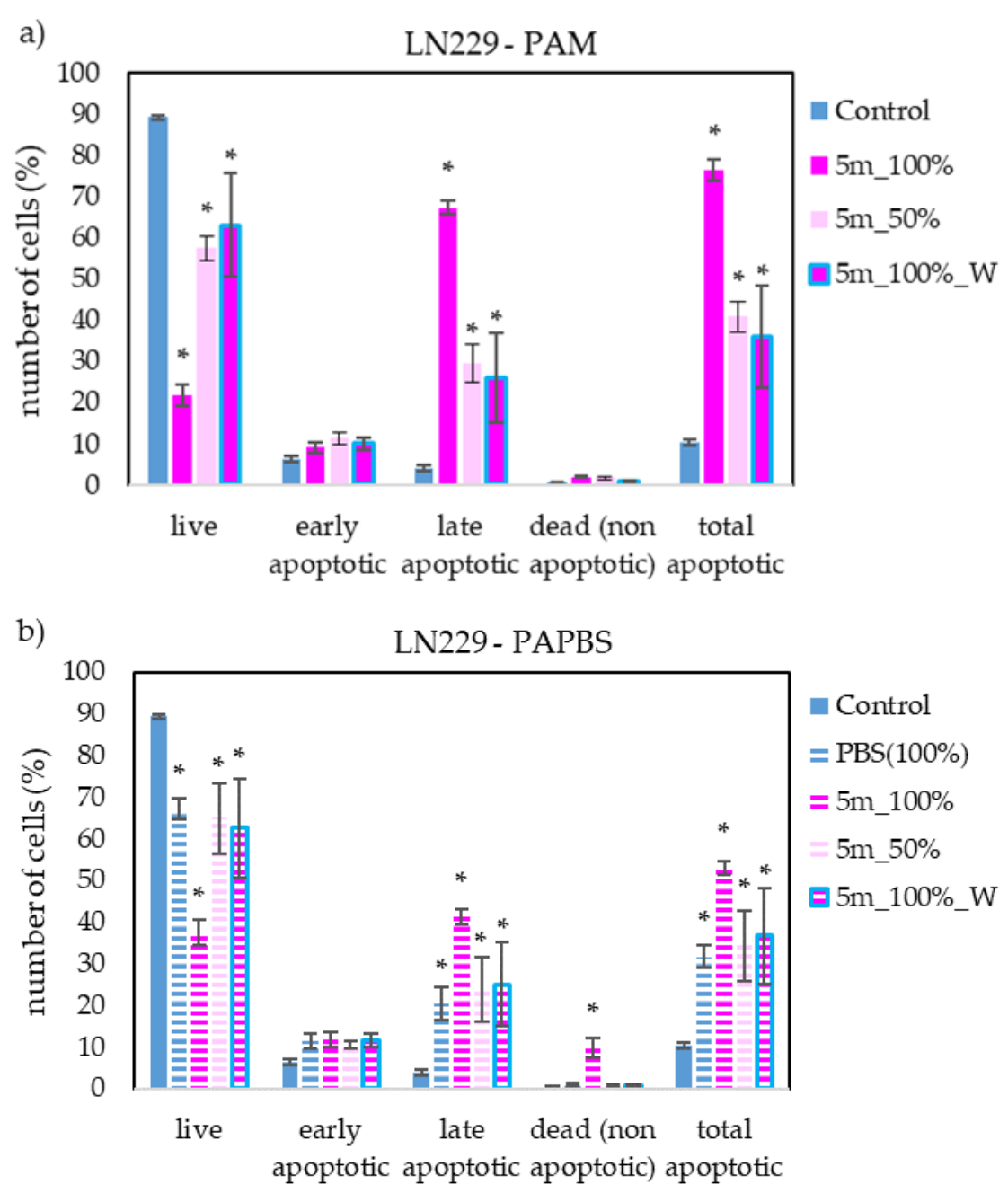

Figure 10. The effect of PAL on apoptosis induction in glioblastoma cells LN229, measured 24 hours after PAL application. Plasma activated medium - PAM (a) or plasma activated PBS - PAPBS (b) activated for 2.5 or 5 minutes in $100 \%$ or $50 \%$ concentration were used. Time of PAL action was 24 hours (without blue frames) or 30 minutes, after which PAL were replaced with untreated medium (W, blue frames). Significance of $100 \%$ PAPBS was tested compared to cells in $100 \%$ PBS, significance of other samples was tested compared to control.

\subsection{Caspase 3 and caspase 7 activity}

To better understand the apoptotic induction and its pathway which is activated in cancer cells after application of PAL, the activity of caspases 3 and 7 in melanoma A375 cells was studied (Figure 11). Plasma activated liquids (both PAM and PAPBS) were activated for 5 minutes and applied in $100 \%$ or $50 \%$ concentration. When the cells were incubated in 50\% PBS (PBS diluted with medium) or in PBS only for 30 minutes, there was not observed difference between the samples and control cells.

A significant number of cells with caspase activity, mostly already dead, was detected. As was observed in apoptosis analysis with annexin $\mathrm{V}$, a significant increase in cells in early apoptosis state 
were detected, when the diluted PAL was applied or the incubation with PAL was only 30 minutes.
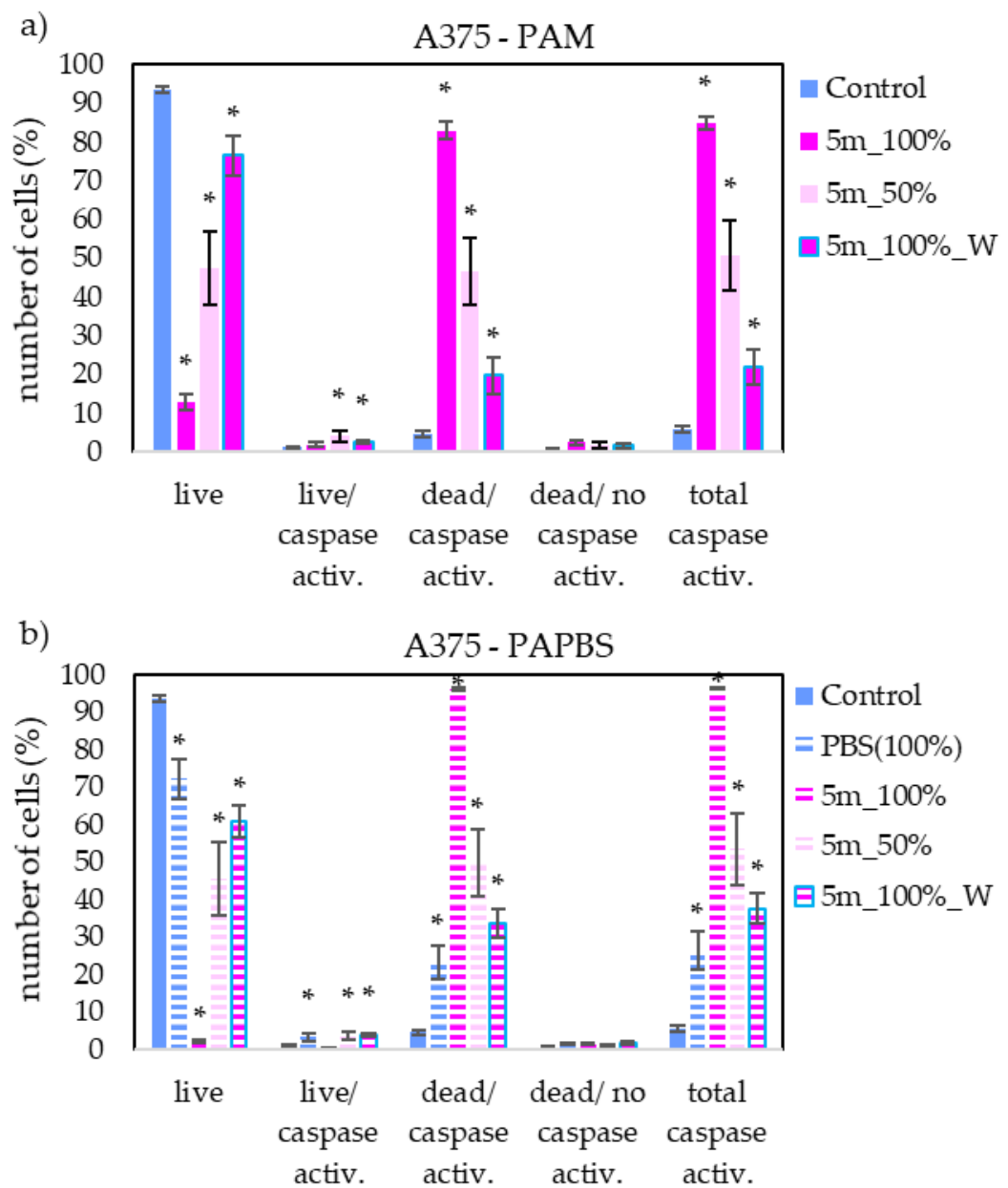

Figure 11. The effect of PAL on caspases $3 / 7$ activity in human melanoma cells A375, measured 24 hours after PAL application. Plasma activated medium - PAM (a) or plasma activated PBS - PAPBS (b) activated for 2.5 or 5 minutes in $100 \%$ or $50 \%$ concentration were used. Time of PAL action was 24 hours or 30 minutes, after which PAL were replaced with untreated medium (W, blue frames). Significance of $100 \%$ PAPBS was tested compared to cells in $100 \%$ PBS.

\subsection{Mitochondrial membrane depolarisation}

To provide more information about the PAL effect on cancer and with focus on the cell death pathway, we measured the loss of mitochondrial membrane potential (depolarisation). This event is often coincident with apoptosis induction but can also occur in necrosis or caspase-independent cell death pathways. We focused on mitochondrial membrane potential change in melanoma A375 cells after treating with PAL activated for 5 seconds (Figure 13). The results are in good agreement with the previous apoptosis test. The most significant difference is in the higher percentage of live cells with depolarised mitochondrial membrane after PAPBS application. 

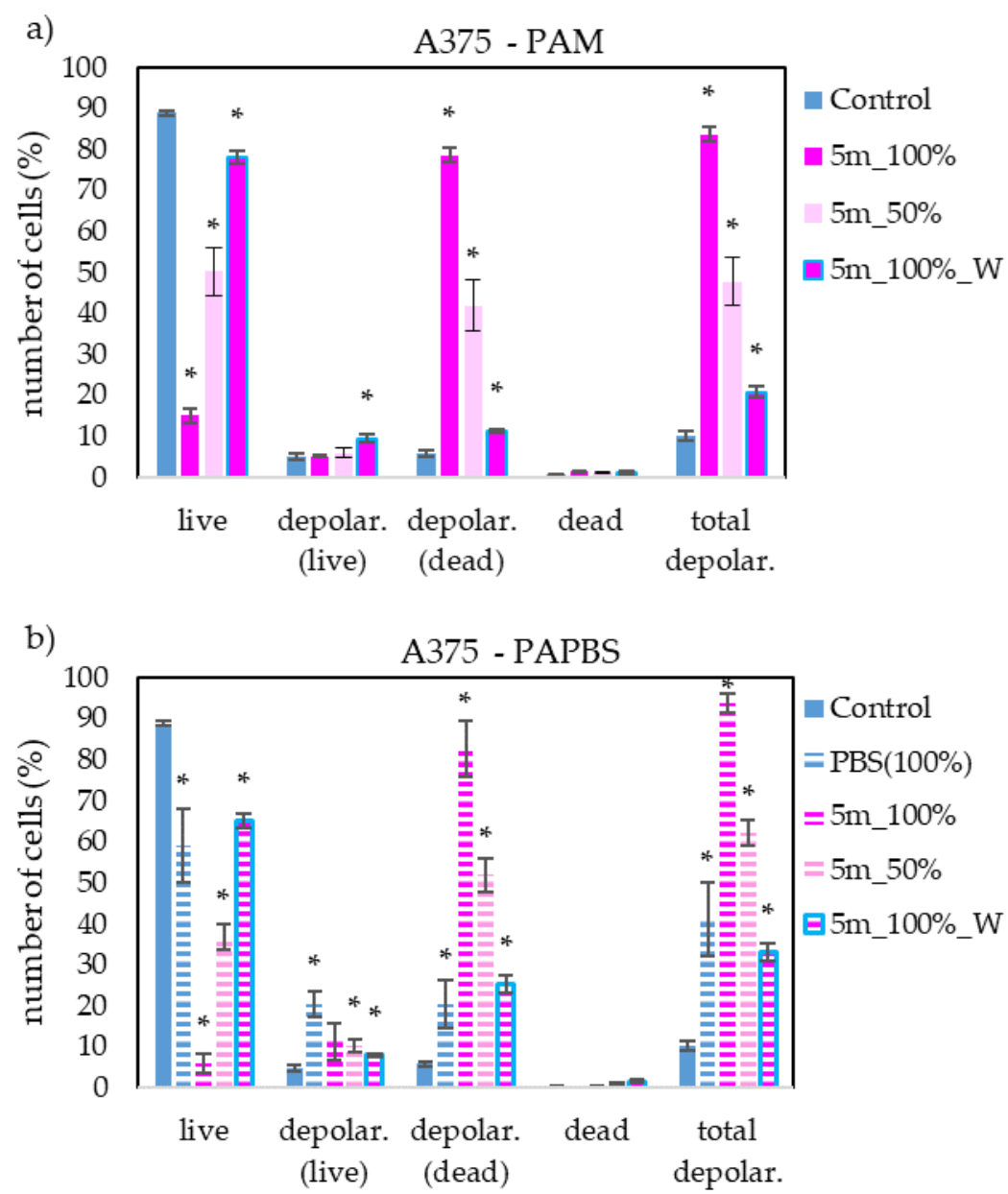

Figure 12. The effect of PAL on mitochondrial membrane depolarisation in human melanoma cells A375, measured 24 hours after PAL application. Plasma activated medium - PAM (a) or plasma activated PBS - PAPBS (b) activated for 2.5 or 5 minutes in $100 \%$ or $50 \%$ concentration were used. Time of PAL action was 24 hours (without blue frames) or 30 minutes, after which PAL were replaced with untreated medium (W, blue frames). Significance of $100 \%$ PAPBS was tested compared to cells in $100 \%$ PBS.

\section{Discussion}

The main objective of this study was testing the effects of plasma activated liquids - plasma activated medium and PBS, on human melanoma cells A375 and compare these results with other epithelial cancer cell lines (glioblastoma cells LN229, pancreatic cancer cells MiaPaCa-2) and normal fibroblasts (HDFa). For cell growth medium and PBS activation with plasma, a streamer corona discharge or a portable plasma pen operating in ambient air was used. We measured around $65 \mu \mathrm{M}$ of generated $\mathrm{H}_{2} \mathrm{O}_{2}$ and $\mathrm{NO}_{2}$ - in PAPBS after 5 minutes treatment of $5 \mathrm{ml}$ in $1 \mathrm{~cm}$ gap, while in the study with kINPen plasma jet generating the plasma discharge in argon, the same treatment time and gap lead to the generation of $800 \mu \mathrm{M} \mathrm{H}_{2} \mathrm{O}_{2}$ and $300 \mu \mathrm{M} \mathrm{NO}_{2}-$ in $2 \mathrm{ml}$ PAPBS [15]. Significantly higher concentration of $\mathrm{H}_{2} \mathrm{O}_{2}$ than $\mathrm{NO}_{2}^{-}$was measured also in PAM after activating by helium plasma jet [37]. We obtained comparable concentrations of both $\mathrm{H}_{2} \mathrm{O}_{2}$ and $\mathrm{NO}_{2}$ - also for other treatment times, which represents an advantage if the reaction between these two specific species is the main point of the plasma effects induced in cancer cells and their selectivity, in line with the previous successful selective anticancer effect obtained by this plasma source [14]. More detailed physical processes and 
chemical reactions leading to the formation of these RONS in the streamer corona discharge in ambient air were described in our previous work [16].

Our results show that both PAM and PAPBS were able to decrease the cell viability in all studied cancer cell lines. Since we focused mostly on melanoma cells, we studied a larger interval of plasma activation times in these cells (from 1.25 to 15 minutes per $5 \mathrm{ml}$ ). Even the shortest activation time significantly lowered the cancer cell viability and we observed the "dose" dependency. With the increasing time and PAL concentration, the cell viability was progressively more reduced, and the 15-minute treatment time reduced the viability to almost $0 \%$, when the cells were incubated in $100 \%$ PAL. A lower but still significant decrease was observed after incubation in 50\% PAL (i.e. PAL added to the growth medium already present in the well in a ratio 1:1). This approach better simulates physiological conditions, when it is not possible to incubate cells only in plasma activated liquids in real tissues, because of the present interstitial liquids.

It has been previously shown that the composition of the growth media can affect the result on the cell viability [22]. We used two cells lines required the identical cell growth medium (A375, MiaPaCa-2), one cell line with a different brand of a very similar medium and glutamine addition (LN229), and healthy primary fibroblasts with a completely different medium. The viability decrease of melanoma and pancreatic cells were comparable. The viability of LN229 cells was lowered more significantly, and we assume that it is rather due to their higher sensitivity to PAM than due to the slightly different composition of medium.

The cell incubation in $100 \%$ PAPBS could lead to the conditions comparable with PAM, but unfortunately 24-hour incubation in PBS is not optimal for the cell growth and their viability was decreased because of the lack of nutrition. Some part of the cells was able to survive 24-hour incubation in pure PBS, however all cells died in 100\% PAPBS (including fibroblasts). Therefore, we decided to perform experiments when the cells were incubated in 100\% PAPBS for 30 minutes only and then we returned the untreated medium in the well. With this approach 30-minute incubation in either PAM or PAPBS was enough to start cell processes which lead to their lower viability and apoptosis. The first few incubation hours are considered as key for anticancer treatments [23], however probably much shorter time is needed, as we also showed in our work [14].

We did not observe any viability reduction of normal fibroblasts after PAM application. This indicates a certain level of the desired selectivity of PAL application to cancer cells, although in some of the studies, viability decrease was observed also in healthy cells. Different types of human fibroblasts were used in studies and it was shown that the treatment with PAM was better tolerated than the direct plasma treatment [38]. PAM activated by He plasma jet decreased the Nuff fibroblasts viability by $20 \%$ [39] and 3 T3 fibroblasts, if PAM was activated for more than 30 seconds [40]. PAM activated by Ar plasma reduced the viability of WI-38 by 40\% [26], however, it had no effect on mammary epithelium cells [41] or human astrocytes [24]. This difference may be due to the different sensitivity of cells to $\mathrm{H}_{2} \mathrm{O}_{2}$. [42].

The viability of HDFa fibroblasts slightly decreased when they were incubated in PBS activated for 5 minutes for all types of application $-100 \%$ and $50 \%$ of PAPBS or in $100 \%$ PAPBS for 30 minutes only, but we did not observe any morphological changes or apoptosis induction, except in $100 \%$ PAPBS. In the study with 1-hour incubation of fibroblasts in PAPBS, the viability of fibroblasts was 
decreased more significantly than the viability of melanoma cells [19], therefore much shorter time of incubation when using PAPBS is needed.

In PAM, the RONS react with medium components which in turn reduces the RONS interacting directly with cells including the hydrogen peroxide concentration [25]. Therefore, it is possible that PAPBS affects healthy cells more sensitive to higher $\mathrm{H}_{2} \mathrm{O}_{2}$ concentrations. And, it was shown, that normal cells are more sensitive to induction of apoptosis with $\mathrm{H}_{2} \mathrm{O}_{2}$, because they are not protected with membrane-associated catalase as cancer cells [43]. Although on the other hand, some studies observed a stronger effect on cancer cells when PAM was added to the cells compared to PAPBS addition [23]. In our work, 50\% PAL in the well induced comparable results in cancer cell lines for both PAM and PAPBS, fibroblasts were slightly more sensitive to PAPBS and less sensitive to PAM.

With 7-ADD and annexin $\mathrm{V}$ staining the apoptosis induction in all studied cancer cell lines was confirmed after all types of PAL treatments with almost no cells in non-apoptotic pathway. We detected no apoptosis in fibroblasts. Furthermore, we studied the caspase 3/7 activity and mitochondrial membrane depolarisation in A375 cells after PAL treatment. A significantly higher caspase 3/7 activity was detected after PAM or PAPBS application. An increased expression of caspase 3 and 8 after PAM and direct plasma treatment of HeLa cells was also observed in [38] and an expression of caspases 3, 7 and 9 after PAM treatment was shown in ovarian cancer cells [29]. Low $\mathrm{H}_{2} \mathrm{O}_{2}$ concentration leads to the caspase-dependent apoptosis and mitochondrial membrane potential change [44]. In a different study on gastric cancer cells, the inhibition of caspase 3 lead to stopping apoptosis induction after the plasma treatment [14]. We detected the depolarization of mitochondrial membrane after PAL application, which suggests that mitochondrial pathway is included in plasma action. It is in good consent with the studies of lipid peroxidation of cell membranes, which are observed in plasma treatments too [45].

There are several differences between direct and indirect plasma cancer cell treatments. The direct plasma treatment affects the cells with UV radiation, electrons, short-lived RONS species and electric field, and depends on the plasma source geometry, gas flows and other parameters. In indirect plasma treatment of liquids, only the RONS created in PAL are responsible for the effects induced in the cells. Although the short-lived species generated in PAL by plasma are already not present when the PAL are applied on cells, the secondary short-lived reactive species can be formed in the PAL from the long-lived RONS and their reactions with medium components. Our plasma source was used in the previous study to induce apoptosis in gastric cells (by using direct treatment and PAM), cervix cancer cells and Ewig sarcoma cells (only direct treatment) - 30 seconds of direct treatment of cells in a medium or the treatment of $1 \mathrm{ml}$ medium was enough to induce apoptosis. On the contrary, the apoptosis was not induced in human diploid fibroblasts (Alpha-1) after direct treatment for less than 1 minute [14].

To explain the cancer vs. normal cell selectivity effect, several possible models were developed. One of the first suggestions is that cancer cells have already a higher ROS level, so their threshold, when more exogenous RONS are added, is lower and therefore lower RONS concentration is needed for the apoptosis induction [46]. This model is mostly not considered as valid. Another suggestion is that cancer cells have less cholesterol in their membranes, which increases the ROS influx into the cell [47]. Or, cancer cells have more aquaporins in their membranes, so more $\mathrm{H}_{2} \mathrm{O}_{2}$ can enter the cell [48], but $\mathrm{H}_{2} \mathrm{O}_{2}$ must be kept in low concentration, when it does not harm healthy cells. Although it is not confirmed, if aquaporins were the reason for the selectivity, it is certain that $\mathrm{H}_{2} \mathrm{O}_{2}$ plays an important 
role in the anticancer effect of PAM. Another recently published explanation of plasma action towards the cancer cells, which also includes its selectivity, is the action of extracellular singlet delta oxygen $\left({ }^{1} \mathrm{O}_{2}\right)$, which is either generated directly by the plasma discharge [49] or is formed in PAL by the reaction between the two main generated RONS - hydrogen peroxide and nitrites $[10,14]$ that were in fact formed in our plasma activated PBS in approximately 1:1 ratio. ${ }^{1} \mathrm{O}_{2}$ formation proceeds through several steps involving peroxynitrite [50,51]. Singlet oxygen can inhibit membraneassociated protective catalase on the cancer cells membranes. Subsequently it leads to the reactivation of $\mathrm{HOCl}$ signalling, which is RONS driven intercellular signalling, $\mathrm{H}_{2} \mathrm{O}_{2}$ influx through aquaporins, activation of mitochondrial apoptotic pathway driven by caspase 3 and caspase 9 [17] and a subsequent cell death through apoptosis [52]. With keeping low $\mathrm{H}_{2} \mathrm{O}_{2}$ concentration, this would lead to significant apoptotic induction in cancer cells without causing any harm to healthy cells. Moreover, the inactivation of membrane-associated catalase could lead to generation of more secondary singlet oxygen, which would inactivate the membrane-associated catalases on the neighbouring cells and result in auto-amplificatory process spreading in the tumour $[32,50]$.

\section{Conclusions}

Many recent studies showed that cold plasma can be successfully used against cancer cells, both in direct action, as well as plasma activated liquids. These liquids act through plasma generated RONS and if the plasma treatment process is well tuned, they can induce apoptosis in cancer cells and do not damage healthy cells.

In this study, a portable plasma pen operating with streamer corona in ambient air was applied to activate two types of liquids suitable for the application on human cells - the cell growth medium and PBS. We measured $\mathrm{H}_{2} \mathrm{O}_{2}, \mathrm{NO}_{2}{ }^{-}$and $\mathrm{NO}_{3}{ }^{-}$concentration in PAPBS. The ratio of generated $\mathrm{H}_{2} \mathrm{O}_{2}$ and $\mathrm{NO}_{2}{ }^{-}$, the species considered to have the key roles in initiating plasma effects on cells and its possible selectivity between cancer and normal cells, was approximately 1:1. This makes the main difference between PAL activated by our ambient air plasma pen and frequently used plasma jets operating with noble gases.

Both PAM and PAPBS decreased the viability and induced apoptosis in three cancer cell lines melanoma cells A375, pancreatic cells MiaPaCa-2 and glioblastoma cells LN229. The effect was confirmed for various plasma treatment times and PAL concentrations. We showed that even 30minute cell incubation in 50\% diluted in medium PAL is sufficient to start cell processes leading to cancer cell apoptosis. Glioblastoma cells appeared to be the most sensitive to PAL. Besides apoptosis detection by standard annexin $\mathrm{V}$ staining, we also focused on more detailed insight on the apoptosis pathways by investigating the action of caspase $3 / 7$ enzymes and mitochondrial membrane depolarization in melanoma cells. The effect of PAL on normal dermal fibroblasts was minimal, with only a little viability decrease for longer time treated PAPBS and with no detected apoptosis (or necrosis) induction. This indicates a generally desired selectivity of plasma and PAL dependent on correctly chosen plasma activation time and PAL concentration. This selectivity, supported by the optimum ratio of hydrogen peroxide and nitrites in PAL, gives a good potential for the following in vivo studies and eventual clinical application in cancer treatment.

Author Contributions: D.S. run and processed the experiments and write the draft of the article. H.G. and V.R. supervised the experiments with cells, reviewed and edited the manuscript. Z.M. initiated and supervised the research, reviewed and edited the manuscript. All authors have read and agreed to the published version of the manuscript.

Funding: This work was supported by Slovak Research and Development Agency APVV-17-0382, APVV-013412 and Comenius University grants UK/281/2021, UK/317/2020 and UK/325/2019.

Acknowledgments: We thank Dr. Jinthe Van Loenhout and prof. Evelien Smits from University of Antwerp, Belgium, for providing us the LN229 cell line. 
Conflicts of Interest: The authors declare no conflict of interest.

\section{References}

[1] Adler, S.; Scherrer, M.; Daschner, F. Costs of low-temperature plasma sterilization compared with other sterilization methods. J. Hosp. Infect. 1998, vol. 40, pp. 125-134, doi: 10.1016/S01956701(98)90091-3.

[2] von Woedtke, T.; Reuter, S.; Masur, K.; Weltmann, K.D. Plasmas for medicine. Physics Reports 2013, vol. 530, pp. 291-320, doi: 10.1016/j.physrep.2013.05.005.

[3] Barekzi, N.; Laroussi, M. Effects of Low Temperature Plasmas on Cancer Cells. Plasma Process. Polym. 2013, vol. 10, DOI 10.100, doi: 10.1002/ppap.201300083.

[4] Metelmann, H.R.; Seebauer, C.; Miller, V.; Fridman, A.; Bauer, G.; Graves, D.; Pouvesle, J.M.; Rutkowski, R.; Schuster, M.; Bekeschus, S.; Wende, K.; Masur, K.; Hasse, S.; Gerling, T.; Hori, M.; Tanaka, H.; Ha Choi, E.; Weltmann, K.D.; Metelmann, P.H.; Von Hoff, D.; von Woedtke, T. Clinical experience with cold plasma in the treatment of locally advanced head and neck cancer. Clin. Plasma Med. 2018, vol. 9, pp. 6-13, doi: 10.1016/j.cpme.2017.09.001.

[5] Kalghatgi, S.; Crystal, M.K.; Cerchar, E.; Torabi, B.; Alekseev, O.; Fridman, A.; Friedman, G.; Azizkhan-Clifford, J. Effects of Non-Thermal Plasma on Mammalian Cells. PLoS One 2011, vol. 6, doi: 10.1371/journal.pone.0016270.

[6] Fridman, G.; Peddinghaus, M.; Ayan, H.; Fridman, A.; Balasubramanian, M.; Gutsol, A.; Brooks, A.; Friedman, G. Blood Coagulation and Living Tissue Sterilization by FloatingElectrode Dielectric Barrier Discharge in Air. Plasma Chem. Plasma Process 2006, vol. 26, pp. 425-442, doi: 10.1007/s11090-006-9024-4.

[7] Panngom, K.; Baik, K.Y.; Nam, M.K.; Han, J.H.; Rhim, H.; Choi, E.H. Preferential killing of human lung cancer cell lines with mitochondrial dysfunction by nonthermal dielectric barrier discharge plasma. Cell Death Dis. 2013, vol. 4, pp. e642-8, doi: 10.1038/cddis.2013.168.

[8] Vermeylen, S.; De Waele, J.; Vanuytsel, S.; De Backer, Joe.; Van der Paal, J.; Ramakers, M.; Leyssens, K.; Marcq, E.; Van Audenaerde, J.; Smits, E.L.J.; Dewilde, S.; Bogaerts, Annemie. Cold atmospheric plasma treatment of melanoma and glioblastoma cancer cells. Plasma Process. Polym. 2016, vol. 13, pp. 1195-1205, 2016, doi: 10.1002/ppap.201600116.

[9] Graves, D.B. The emerging role of reactive oxygen and nitrogen species in redox biology and some implications for plasma applications- J. Phys. D. Appl. Phys. 2012, vol. 45, doi: 10.1088/0022-3727/45/26/263001.

[10] Bauer, G.; Graves, D.B. Mechanisms of Selective Antitumor Action of Cold Atmospheric Plasma-Derived Reactive Oxygen and Nitrogen Species. Plasma Process. Polym. 2016, doi: 10.1002/ppap.201600089.

[11] Harley, J.C.; Suchowerska, N.; Mckenzie, D.R. Cancer treatment with gas plasma and with gas plasma-activated liquid: positives, potentials and problems of clinical translation. Biophys. Rev. 2020, vol. 12, pp. 989-1006, doi: 10.1007/s12551-020-00743-z/Published.

[12] Tresp, H.; Hammer, M.U.; Weltmann, K.D.; Reuter, S. Effects of atmosphere composition and liquid type on plasma-generated reactive species in biologically relevant solutions. Plasma Med. 2013, vol. 3, pp. 45-55, doi: 10.1615/PlasmaMed.2014009711.

[13] Murakami, T.; Niemi, K.; Gans, T.; O'Connell, D.; Graham, W.G. Chemical kinetics and reactive species in atmospheric pressure helium-oxygen plasmas with humid-air impurities. Plasma Sources Sci. Technol. 2012, vol. 22, p. 015003, doi: 10.1088/0963-0252/22/1/015003. 
[14] Bauer, G.; Sersenová, D.; Graves, D.B.; Machala, Z. Cold Atmospheric Plasma and PlasmaActivated Medium Trigger RONS-Based Tumor Cell Apoptosis. Sci. Rep. 2019, vol. 9, doi: 10.1038/s41598-019-50291-0.

[15] Van Boxem, W.; Van Der Paal, J.; Gorbanev, Y.; Vanuytsel, S.; Smits, E. Anti-cancer capacity of plasma- treated PBS : effect of chemical composition on cancer cell cytotoxicity. Sci. Rep. 2017, vol. 7, doi: 10.1038/s41598-017-16758-8.

[16] Machala, Z.; Tarabova, B.; Sersenova, D.; Janda, M.; Hensel, K. Chemical and antibacterial effects of plasma activated water : correlation with gaseous and aqueous reactive oxygen and nitrogen species, plasma sources and air flow conditions. J. Phys. D. Appl. Phys. 2019, vol. 52, doi: 10.1088/1361-6463/aae807.

[17] Bauer, G. The synergistic effect between hydrogen peroxide and nitrite, two long-lived molecular species from cold atmospheric plasma, triggers tumor cells to induce their own cell death. Redox Biol. 2019, vol. 26, p. 101291, doi: 10.1016/j.redox.2019.101291.

[18] Kurake, N.; Tanaka, H.; Ishikawa, K.; Kondo, T.; Sekine, M.; Nakamura, K.; Kajiyama, H.; Kikkawa, F.; Mizuno, M.; Hori, M.; Cell survival of glioblastoma grown in medium containing hydrogen peroxide and/or nitrite, or in plasma-activated medium. Arch. Biochem. Biophys. 2016, vol. 605, pp. 102-108, doi: 10.1016/j.abb.2016.01.011.

[19] Girard, P.; Arbabian, A.; Fleury, M.; Bauville, G.; Puech, V.; Dutreix, M.; Sousa, J.S. Synergistic Effect of H 2 O 2 and NO 2 in Cell Death Induced by Cold Atmospheric He Plasma. Sci. Rep. 2016, vol. 6, doi: 10.1038/srep29098.

[20] Jablonowski, H.; Von Woedtke, T. Research on plasma medicine-relevant plasma-liquid interaction: What happened in the past five years?, Clin. Plasma Med. 2015, vol. 3, pp. 42-52, doi: 10.1016/j.cpme.2015.11.003.

[21] Boehm, D.; Heslin, C.; Cullen, P.J.; Bourke, P. Cytotoxic and mutagenic potential of solutions exposed to cold atmospheric plasma. Sci. Rep. 2016, vol. 6, doi: 10.1038/srep21464.

[22] Adachi, T.; Tanaka, H.; Nonomura, S.; Hara, H.; Kondo, S. Free Radical Biology and Medicine Plasma-activated medium induces A549 cell injury via a spiral apoptotic cascade involving the mitochondrial - nuclear network. Free Radic. Biol. Med. 2015, vol. 79, pp. 28-44, doi: 10.1016/j.freeradbiomed.2014.11.014.

[23] Yan, D.; Cui, H.; Zhu, W.; Nourmohammadi, N.; Milberg, J.; Zhang, L.G.; Sherman, J.H.; Keidar, M. The Specific Vulnerabilities of Cancer Cells to the Cold Atmospheric PlasmaStimulated Solutions. Sci. Rep. 2017, vol. 7, doi: 10.1038/s41598-017-04770-x.

[24] Tanaka, H.; Mizuno, M.; Ishikawa, K.; Nakamura, K.; Kajiyama, H.; Kano, H.; Kikkawa, F.; Hori, M. Plasma-Activated Medium Selectively Kills Glioblastoma Brain Tumor Cells by Down- Regulating a Survival Signaling Molecule , AKT Kinase. Plasma Med. 2011, vol. 1, pp. 265-277.

[25] Yan, D.; Talbot, A.; Nourmohammadi, N.; Cheng, X.; Canady, J.; Sherman, J.; Keidar, M. Principles of using Cold Atmospheric Plasma Stimulated Media for Cancer Treatment. Sci. Rep. 2015, vol. 5, doi: 10.1038/srep18339.

[26] Tanaka, H.; Mizuno, M.; Ishikawa, K.; Nakamura, K.; Utsumi, F.; Kajiyama, H.; Kano, H.; Maruyama, S.; Kikkawa, F.; Hori, M. Cell survival and proliferation signaling pathways are downregulated by plasma-activated medium in glioblastoma brain tumor cells. Plasma Med. 2012, vol. 2, pp. 207-220, doi: 10.1615/PlasmaMed.2013008267.

[27] Mohades, S.; Laroussi,M.; Sears, J.; Barekzi, N.; Razavi, H. Evaluation of the effects of a plasma 
activated medium on cancer cells. Phys. Plasmas 2015, vol. 22, doi: 10.1063/1.4933367.

[28] Vandamme, M.; Robert, E.; Lerondel, S.; Sarron, V.; Ries, D.; Dozias, S.; Sobilo, J.; Gosset, D.; Kieda, C.; Legrain, B.; Pouvesle, J.M.; Pape, A.L. ROS implication in a new antitumor strategy based on non-thermal plasma. Int. J. Cancer 2012, vol. 130, pp. 2185-2194, doi: 10.1002/ijc.26252.

[29] Nakamura, K.; Peng, Y.; Utsumi, F.; Tanaka, H.; Mizuno, M. Novel Intraperitoneal Treatment With Non-Thermal Plasma- Activated Medium Inhibits Metastatic Potential of Ovarian Cancer Cells. Sci. Rep. 2017, vol. 7, doi: 10.1038/s41598-017-05620-6.

[30] Utsumi, F.; Kajiyama, H.; Nakamura, K.; Tanaka, H.; Mizuno, M. Effect of Indirect Nonequilibrium Atmospheric Pressure Plasma on Anti-Proliferative Activity against Chronic Chemo-Resistant Ovarian Cancer Cells In Vitro and In Vivo. PLoS ONE ONE 2013, vol. 8, doi: 10.1371/journal.pone.0081576.

[31] Lin, A.; Truong, B.; Patel, S.; Kaushik, N.; Choi, E.H.; Fridman, G.; Fridman, A.; Miller, V. Nanosecond-Pulsed DBD Plasma-Generated Reactive Oxygen Species Trigger Immunogenic Cell Death in A549 Lung Carcinoma Cells through Intracellular Oxidative Stress. Int. J. Mol. Sci. 2017, vol. 18, doi: 10.3390/ijms18050966.

[32] Bauer, G.; Sersenová, D.; Graves, D.B.; Machala, Z. Dynamics of Singlet Oxygen-Triggered, RONS-Based Apoptosis Induction after Treatment of Tumor Cells with Cold Atmospheric Plasma or Plasma-Activated Medium. Sci. Rep. 2019, vol. 9, doi: 10.1038/s41598-019-50329-3.

[33] Simões, M.C.F.; Sousa, J.J.S.; Pais, A.A.C.C. Skin cancer and new treatment perspectives: A review. Cancer Lett. 2015, vol. 357, pp. 8-42, doi: 10.1016/j.canlet.2014.11.001.

[34] Fiers, W.; Beyaert, R.; Declercq, W.; Vandenabeele, P. More than one way to die: apoptosis, necrosis and reactive oxygen damage. Oncogene 1999, vol. 18, pp. 7719-7730.

[35] Tanaka, H.; Ishikawa, K.; Mizuno, M.; Toyokuni, S.; Kajiyama, H.; Kikkawa, F.; Metelmann, H.R.; Hori, M.; State of the art in medical applications using non-thermal atmospheric pressure plasma. Rev. Mod. Plasma Phys. 2017, vol. 1, doi: 10.1007/s41614-017-0004-3.

[36] Hirst, A.M.; S.; Mann, V.M.; Maitland, N.J.; O'Connell, D.; Frame, F.M. Low-temperature plasma treatment induces DNA damage leading to necrotic cell death in primary prostate epithelial cells. Br. J. Cancer 2015, vol. 112, pp. 1536-1545, doi: 10.1038/bjc.2015.113.

[37] Chauvin, J.; Judée, F.; Yousfi, M.; Vicendo, P.; Merbahi, N.Analysis of reactive oxygen and nitrogen species generated in three liquid media by low temperature helium plasma jet. Sci. Rep. 2017, vol. 7, doi: 10.1038/s41598-017-04650-4.

[38] Jezeh, M.A. Direct cold atmospheric plasma and plasma - activated medium effects on breast and cervix cancer cells,. Plasma Process. Polym. 2020, vol 17, doi: 10.1002/ppap.201900241.

[39] Jo, A.; Joh, H.M.; Chung, T.H.; Chung, J.W. Anticancer Effects of Plasma-Activated Medium Produced by a Microwave-Excited Atmospheric Pressure Argon Plasma Jet. Oxid. Med. Cell. Longev. 2020, vol. 2020, doi: 10.1155/2020/4205640 .

[40] Xu, G.M.; Hao, Y.; Sun, M.Y.; Liu, J.R.; Shi, X.M.; Zhang, G.J. Characteristics of Plasma Activated Medium Produced by Atmospheric Pressure Helium Plasma Jet and Its Selective Effect on Malignant Melanoma and Normal. IEEE Trans. Plasma Sci. 2020, vol. 48, pp. 587-595.

[41] Kurake, N.; Tanaka, H.; Ishikawa, K.; Kondo, T.; Sekine, M.; Nakamura, K.; Kajiyama, H.; Kikkawa, F.; Mizuno, M.; Hori, M. Cell survival of glioblastoma grown in medium containing hydrogen peroxide and/or nitrite, or in plasma-activated medium. Arch. Biochem. Biophys. 2016, vol. 605, pp. 102-108, doi: 10.1016/j.abb.2016.01.011. 
[42] Horiba, M.; Kamiya, T.; Hara, H.; Adachi, T. Cytoprotective effects of mild plasma-activated medium against oxidative stress in human skin fibroblasts. Sci. Rep. 2017, vol. 7, doi: 10.1038/srep42208.

[43] Heinzelmann, S. Bauer, G. Multiple protective functions of catalase against intercellular apoptosis-inducing ROS signaling of human tumor cells. Biol. Chem. 2010, vol. 391, pp. 675693, doi: 10.1515/BC.2010.068.

[44] Tochigi, M.; Inoue, T.; Suzuki-karasaki, M.; Ochiai, T.; Ra, C.; Suzuki-karasaki, Y. Hydrogen peroxide induces cell death in human TRAIL-resistant melanoma through intracellular superoxide generation. Int. J. Oncol. 2013, vol. 42, pp. 863-872, doi: 10.3892/ijo.2013.1769.

[45] Keidar, M.; Shashurin, A.; Volotskova, O.; Stepp, M.A.; Srinivasan, P.; Sandler, A.; Trink, B. Cold atmospheric plasma in cancer therapy Cold atmospheric plasma in cancer therapy a). Phys. Plasmas 2013, vol. 20, doi: 10.1063/1.4801516.

[46] Gorrini, C.; Harris, I.S.; Mak, T.W. Modulation of oxidative stress as an anticancer strategy. Nat. Rev. Drug Discov. 2013, vol. 12, pp. 931-947, doi: 10.1038/nrd4002.

[47] Van Der Paal, J.; Verheyen, C.; Neyts, E.C.; Bogaerts, A. Hampering Effect of Cholesterol on the Permeation of Reactive Oxygen Species through Phospholipids Bilayer: Possible Explanation for Plasma Cancer Selectivity. Sci. Rep. 2017, vol. 7, doi: 10.1038/srep39526.

[48] Verkman, A.; Hara-Chikuma, M.; Papadopoulos, M. Aquaporins-new players in cancer biology. J Mol Med 2008, vol. 86, pp. 523-529, doi: 10.1007/s00109-008-0303-9.Aquaporins.

[49] Sousa, J.S.; Bauville, G.; Lacour, B.; Puech, V.; Touzeau, M.; Ravanat, J.L. DNA oxidation by singlet delta oxygen produced by atmospheric pressure microdischarges. Appl. Phys. Lett. 2010, vol. 97, pp. 3-5, doi: 10.1063/1.3499362.

[50] Bauer, G. Autoamplificatory singlet oxygen generation sensitizes tumor cells for intercellular apoptosis-inducing signaling," Mech. Ageing Dev. 2018, vol. 172, pp. 59-77, doi: 10.1016/j.mad.2017.11.005.

[51] Lukes, P.; Dolezalova, E.; Sisrova, I.; Clupek, M. Aqueous-phase chemistry and bactericidal effects from an air discharge plasma in contact with water: evidence for the formation of peroxynitrite through a pseudo-second-order post-discharge reaction of $\mathrm{H}_{2} \mathrm{O}_{2}$ and $\mathrm{HNO}_{2}$. Plasma Sources Sci. Technol. 2014, vol. 23, p. 015019, doi: 10.1088/0963-0252/23/1/015019.

[52] Riethmüller, M., Burger, N., Bauer, G. Redox Biology Singlet oxygen treatment of tumor cells triggers extracellular singlet oxygen generation, catalase inactivation and reactivation of intercellular apoptosis-inducing signaling," Redox Biol. 2015, vol. 6, pp. 157-168, doi: 10.1016/j.redox.2015.07.006. 